\title{
Characterization of serum adhesive proteins that block tumor necrosis factor-mediated cell death
}

\author{
Nan-Shan Chang ${ }^{1,2}$, Nicole Joki ${ }^{1}$, Jeff Mattison ${ }^{1}$, Tuan Dinh ${ }^{1}$ \\ and Seenian John ${ }^{1}$ \\ ${ }^{1}$ Guthrie Research Institute, Laboratory of Molecular Immunology, Guthrie \\ Medical Center, Sayre, Pennsylvania 18840, USA \\ 2 corresponding author: N.-S. Chang, Guthrie Research Institute, 1 Guthrie \\ Square, Sayre, Pennsylvania 18840; fax: (717) 882-5151; \\ email: nschang@inet.guthrie.org
}

Received 4.3.97; revised 10.6.97; accepted 14.7.97

Edited by J. Cidlowski

\begin{abstract}
Previously we have shown that TGF- $\beta 1$ protects murine L929 fibroblasts from TNF/ActD-mediated cell death by inducing the expression of an extracellular matrix TNF-resistance triggering (TRT) protein. TRT promotes TNF-resistance via activation of tyrosine and serine/threonine kinases in L929 cells. To examine the presence of TRT activity in serum (designated STRT), human sera were diluted, treated with or without PMSF and subjected to sequential ammonium sulfate precipitation (ASP). Aliquots of the ASP protein fractions were coated onto 96 -well plates, followed by thorough washing. When L929 cells were seeded and cultured on the wells coated with STRT proteins, these cells resisted killing by TNF, TNF/ActD, doxorubicin and serum deprivation, but not by anti-Fas/ActD, staurosporine and ActD. STRT activity was found at the $15 \%$ ASP fraction of untreated sera, but shifted to the $20 \%$ ASP fraction of PMSFtreated sera. Two likely STRT proteins of approximately 226 and $265 \mathrm{kDa}$ were found in these fractions, compared to the corresponding nonfunctional ASP fractions. Functionally, STRT was inactivated by trypsin, but not by $5 \mathrm{M}$ salt, various serine and/or cysteine protease inhibitors, and antibodies against fibronectin, vitronectin, C1q, histidine-rich glycoprotein, CD44, chondroitin sulfate and hyaluronic acid. STRT failed to alter the expression of proteins involved in apoptosis such as RIP, ICH-1 $\mathrm{L}_{\mathrm{L}}, \mathrm{BCL}-\mathrm{x}$, TIAR and $\mathrm{I}_{\kappa} \mathrm{B} \alpha$, and could not induce $\mathrm{I}_{\kappa} \mathrm{B} \alpha$ degradation. The induced TNFresistance could be reversed by treatment of STRTstimulated cells with testicular hyaluronidase, as well as with tyrosine kinase inhibitors tyrophostin, lavendustin A and AG-490 (a selective inhibitor of JAK2 kinase). However, the STRT function could not be blocked by the MEK kinase inhibitor PD98059 and the NF- $k$ B inhibitors curcumin and a synthetic inhibitor peptide for NF- $\kappa$ B translocation. Together, our data suggest that tyrosine kinase activation is involved in the STRT-mediated resistance to TNF and TNF/ ActD in L929 cells.
\end{abstract}

Keywords: tumor necrosis factor; tyrosine kinase inhibitors; transforming growth factor $\beta$; serum adhesive proteins; L929 cells

Abbreviations: TGF- $\beta 1$, transforming growth factor beta 1; TNF (or TNF- $\alpha$ ), tumor necrosis factor; ActD, actinomycin D; TRT, TNF-resistance triggering protein; STRT, serum TRT; FBS, fetal bovine serum; NHS, normal human serum; ASP, ammonium sulfate precipitation; PMSF, phenylmethylsulfonyl fluoride; PBS, phosphate-buffered saline; anti-Fas/ActD, antiFas antibodies plus actinomycin D; IEF, isoelectric focusing

\section{Introduction}

Transforming growth factor beta 1 (TGF- $\beta 1$ ) protects several cancer cells from the cytotoxic effect of tumor necrosis factor alpha (TNF or TNF- $\alpha$ ) (Shepard and Lewis, 1988; Kamijo et al, 1988; Sugarman et al, 1989; Belizario and Dinarello, 1991; Chang, 1995). We have determined that protection of murine L929 fibrosarcoma cells by TGF- $\beta 1$ from TNF killing involves rapid activation of cellular protein-tyrosine kinases in these cells (Chang, 1995). The raised tyrosine phosphorylation appears to alter the TNF killing pathway. Inhibitors of tyrosine kinases such as tyrphostin and lavendustin $A$ abolish the protein-tyrosine phosphorylation and the TGF- $\beta 1$-induced TNF resistance (Chang, 1995). Additionally, TGF- $\beta 1$ stimulates L929 cells to secrete a novel extracellular matrix TNFresistance triggering (TRT) protein. This protein activates cellular protein tyrosine and serine/threonine kinases and further sustains TGF- $\beta 1$-mediated TNF-resistance (Chang, 1995).

The extracellular matrix TRT protein resists inactivation by heat $\left(60^{\circ} \mathrm{C}, 30 \mathrm{~min}\right)$, collagenase, $\alpha 2$-macroglobulin, heparin, antibodies against TGF- $\beta$ S (TGF- $\beta 1,-\beta 2$ and $-\beta 3$ ), and limited trypsin digestion (Chang, 1995). Metabolic labeling, functional and sequencing analyses revealed that TRT is a $46 \mathrm{kDa}$ protein containing a unique $\mathrm{N}$-terminal sequence (Chang et al, unpublished).

In the present study we demonstrate the presence of TRT functions in human sera, designated STRT hereafter. Human sera were diluted $(1: 3)$ in phosphate buffered saline (PBS) and subjected to sequential ammonium sulfate precipitation (ASP), and aliquots of the fractionated protein preparations were coated onto polystyrene-based 96-well microtiter plates for examining the STRT activity. When L929 cells were seeded onto the STRT-containing protein matrix, the cells became refractory to killing by TNF, TNF/ Actinomycin $D($ ActD), doxorubicin and serum deprivation. However, STRT failed to prevent cell death by staurosporine, ActD and anti-Fas/ActD. Characteristics of STRT were examined in this study. 


\section{Results}

\section{STRT induction of L929 cell resistance to TNF and TNF/ActD}

Human sera were diluted and treated with or without PMSF $(1 \mathrm{mM})$, followed by sequential precipitation of proteins with $10,15,20,25,30$ and $40 \%$ ammonium sulfate. Aliquots of the resulting ASP fractions were coated onto 96-well microtiter plates for $3 \mathrm{~h}$ at $37^{\circ} \mathrm{C}$, followed by thorough washing. When L929 cells were seeded and cultured overnight on the wells coated with STRT proteins, the cells resisted TNF/ActD-mediated cell death. STRT activity was found at the 15\% ASP fraction
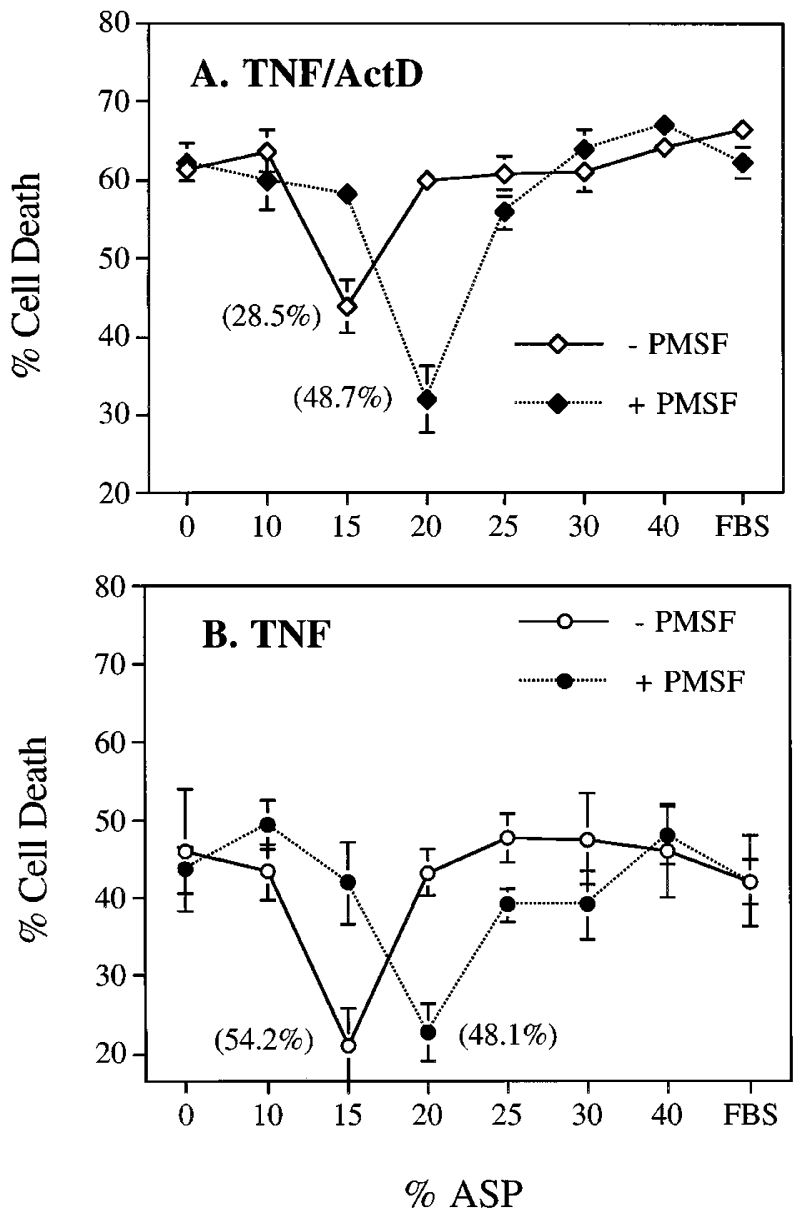

Figure 1 Inhibition of TNF/ActD-, and TNF-mediated cell death by human serum STRT. Human sera was diluted $(1: 3)$ in PBS, treated with or without PMSF (1 mM), and subjected to ammonium sulfate precipitation (ASP), as described in Materials and Methods. Ninety-six well microtiter plates were coated with $30 \mu$ l of the ASP fractions $(10-40 \%)$ for $3 \mathrm{~h}$, followed by washing twice with $5 \mathrm{M} \mathrm{NaCl}$, three times with sterile water and three times with PBS. For controls, $30 \mu \mathrm{l}$ of PBS buffer (regarded as $0 \%$ ) and undiluted FBS were coated onto the microtiter plates. L929 cells were then seeded onto the plates, cultured overnight, and treated with (A) TNF (10 units $/ \mathrm{ml}) / \operatorname{ActD}(1 \mu \mathrm{g} / \mathrm{ml})$, or (B) TNF (1000 units $/ \mathrm{ml}$ ) for $24 \mathrm{~h}$. Note that the STRT activity was at the $15 \%$ ASP fraction of untreated serum, but shifted to the 20\% ASP of PMSF-treated serum. STRT significantly inhibited TNF/ActD- and TNF-mediated cell death compared to PBS buffer controls $(P<0.01$; experiments versus buffer controls. Student's $t$-tests; $n=12$ ). The extent of STRT-induced TNF-resistance is shown in each bracket of untreated serum, but shifted to the $20 \%$ ASP fraction of PMSF-treated serum (Figure $1 \mathrm{~A}$ ). In controls, no protective activity was found by coating 96-well plates with undiluted fetal bovine serum (FBS) or PBS buffer (Figure 1A). Without ActD, TNF-mediated cell death was also blocked by STRT, which was found at the 15\% ASP of untreated serum, and at the $20 \%$ ASP of PMSFtreated serum (Figure 1B). The induced resistance could be further increased by raising the amount of STRT proteins for coating onto the plates (data not shown). Under the above experimental conditions, no apparent cell death was found by culturing L929 cells in 96-well plates coated with serum proteins, PBS, or without coating (data not shown).

Shown in the Figure 2 is the profile of plastic-bound proteins from both 15 and $20 \%$ ASP fractions of serum pretreated with or without PMSF. The adhered proteins were harvested by a sample buffer containing $\mathrm{SDS} / \beta$ mercaptoethanol (Chang, 1995) and analyzed by reducing SDS-PAGE and Coomassie blue stain. Compared to the proteins from the nonfunctional ASP fractions, two likely STRT proteins of approximately 226 and $265 \mathrm{kDa}$ were present at the functional 15\% ASP of untreated

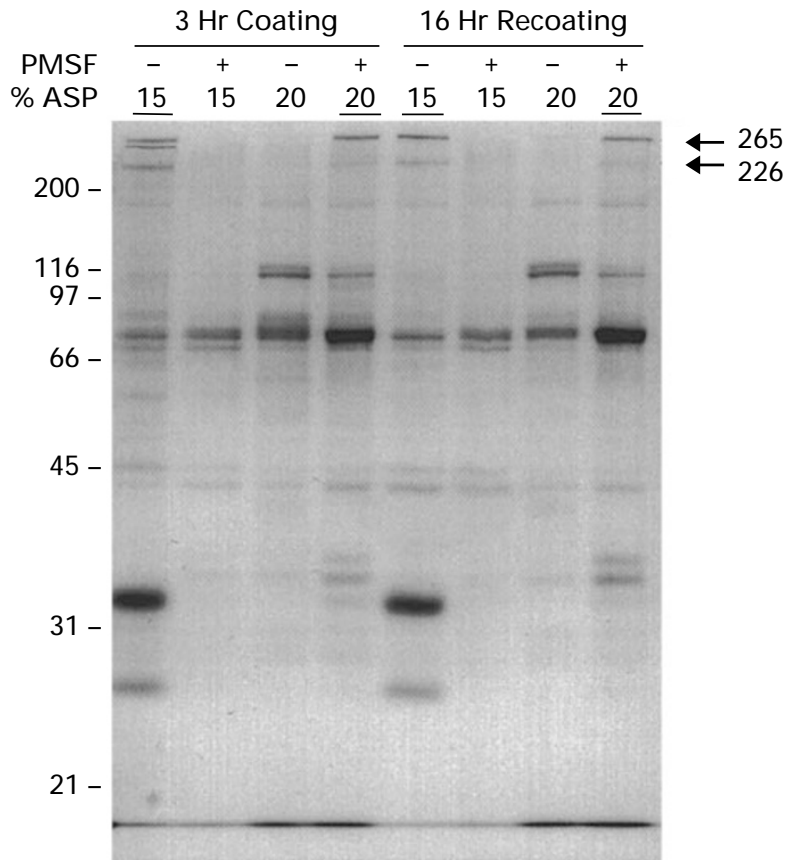

Figure 2 Plastic adhered STRT proteins. One milliliter of 15 and $20 \%$ ASP fractions of both untreated and PMSF-treated sera were coated onto $60 \mathrm{~mm}$ petri dishes for $3 \mathrm{~h}$ at $37^{\circ} \mathrm{C}$ (non-dry coating with lids on), followed by harvesting the supernatants and washing the petri dishes twice with $5 \mathrm{M} \mathrm{NaCl}$, three times with sterile water and three times with PBS. The harvested supernatants were again recoated onto petri dishes overnight at $37^{\circ} \mathrm{C}$, followed by thoroughly washing the dishes. The plastic adhered proteins were harvested by scraping the plates with cell scrapers in $250 \mu \mathrm{l}$ of an SDS-sample buffer (Chang, 1995) and analyzed by a $10 \%$ reducing SDS-PAGE. Compared to the nonfunctional ASP fractions $(20 \%$ of untreated serum and $15 \%$ of PMSF-treated serum), two likely STRT proteins of approximately 226 and $265 \mathrm{kDa}$ were present in the functional $15 \%$ ASP of untreated serum and $20 \%$ ASP of PMSF-treated serum (see underlined fractions and arrows). No apparent protein degradation was found during this repeat coating. The molecular weight standard is shown on the left 
serum and $20 \%$ ASP of PMSF-treated serum (Figure 2; see underlined and arrows). Coating of serum proteins onto 96-well microtiter plates for $3 \mathrm{~h}$ at $37^{\circ} \mathrm{C}$ was sufficient to be able to observe the STRT activity, whereas prolonging the coating up to $24 \mathrm{~h}$ did not decrease the STRT function (data not shown). No apparent degradation of the plastic adhered proteins was observed by repeat coating of the harvested ASP preparations (Figure 2). Normally, repeat coating for 1-2 times could not reduce the STRT function (data not shown).

In the above experiments, the protein-coated wells were washed thoroughly with $5 \mathrm{M} \mathrm{NaCl}$, sterile Milli-Q water, and PBS. A direct washing of the wells with PBS produced no significant differences to the above washing conditions (data not shown). Total protein coated onto plastic plates was less than $0.1 \%$ of the total protein added, as determined by the BioRad Protein Assay. That is, each well was normally coated with $20-100 \mathrm{ng}$ of serum proteins. Without coating, aliquots $(5-20 \mu \mathrm{l})$ of the ASP protein fractions when directly added to $L 929$ cells for $16-24 \mathrm{~h}$ in culture failed to protect these cells against the cytotoxic actions of TNF and TNF/ActD (data not shown).

\section{STRT inhibition of cell death by serum deprivation and doxorubicin, but not by anti-Fas/ActD, ActD and staurosporine}

In addition to the inhibition of TNF and TNF/ActD-mediated cell death, STRT also blocked cell death caused by serum deprivation and doxorubicin (Figure 3). However, it had no inhibitory effect on cell death by anti-Fas/ActD, ActD and staurosporine (Figure 3). The STRT proteins were from the $20 \%$ ASP of PMSF-treated serum.

\section{Failure of STRT in alteration of the expression of proteins involved in apoptosis}

Stimulation of L929 cells with STRT for $24 \mathrm{~h}$ failed to result in alteration of the expression of RIP (Stanger et al, 1995), ICH$1_{\mathrm{L}}$ (Wang et al, 1994), BCL-x (Boise et al, 1993), TIAR (Taupin et al, 1995), and $\mathrm{I}_{\kappa} \mathrm{B} \alpha$ (Baeuerle and Baltimore, 1988; Miyamoto et al, 1994), compared to control cells (Figure 4). No degradation of $I_{\kappa} \mathrm{B} \alpha$ was found in both control and STRTstimulated L929 cells (Figure 4). Similar results were observed by stimulation of L929 cells with STRT for $5 \mathrm{~h}$ (data not shown). Both up-regulation of BCL-x and downregulation of RIP, ICH-1 ${ }_{\mathrm{L}}$ and TIAR may result in increased TNF or TNF/ActD resistance. Degradation of $\mathrm{I}_{\kappa} \mathrm{B} \alpha$ indicates the activation of NF- $\kappa$ B (Baeuerle and Baltimore, 1988; Miyamoto et al, 1994). The STRT proteins were from the $20 \%$ ASP of PMSF-treated sera from two healthy individuals.

\section{Abrogation of STRT function by trypsin, but not by antibodies against matrix proteins and cell surface components}

To neutralize STRT function, both trypsin and antibodies against fibronectin, vitronectin (S-protein), histidine-rich

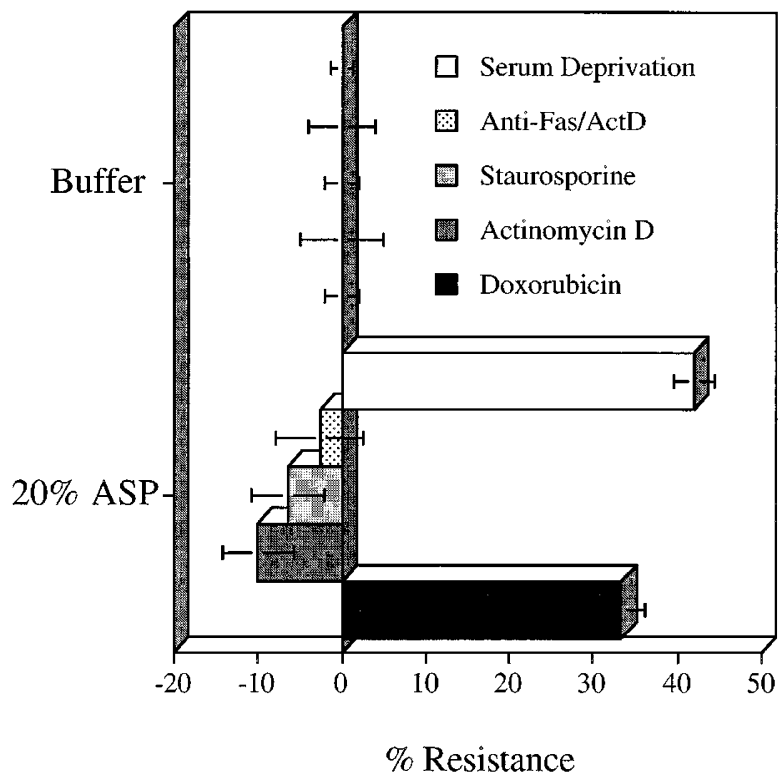

Figure 3 Inhibition of serum deprivation- and doxorubicin-mediated cell death by STRT. L929 cells were seeded onto 96 -well microtiter plates which were precoated with STRT proteins from the 20\% ASP fraction of PMSFtreated serum. In controls, PBS buffer was used for coating. After culturing L929 cells on the STRT or control matrix for $24 \mathrm{~h}$, the cells were subjected to serum deprivation, or exposure to monoclonal anti-Fas antibodies $(500 \mathrm{ng} / \mathrm{ml}) /$ $\operatorname{ActD}(1 \mu \mathrm{g} / \mathrm{ml})$, staurosporine $(500 \mathrm{nM})$, ActD $(10 \mu \mathrm{g} / \mathrm{ml})$, or doxorubicin $(10 \mu \mathrm{g} /$ $\mathrm{ml})$ for $24 \mathrm{~h}$. Compared to buffer controls, STRT significantly inhibited cell death by serum deprivation and doxorubicin $(P<0.01$; Student's $t$-tests; $n=12$ ), but failed to block cell death by anti-Fas/ActD, ActD and staurosporine $(P>0.1)$

glycoprotein, complement C1q, CD44, chondroitin sulfate and hyaluronic acid were used to treat the coated STRT proteins. Trypsin completely abolished the STRT function in blocking TNF/ActD killing (Figure 5). However, none of these antibodies had inhibitory effects against STRT (Figure 5). In controls, trypsin or antibodies alone when coated onto the untreated 96-well plates (followed by washing) had no effect on the modulation of TNF/ActD killing (Figure 5). Interestingly, antibodies against vitronectin and histidine-rich glycoprotein when interacting with the STRT protein matrix significantly increased L929 cell resistance to TNF/ActD killing (Figure 5). Seeding of L929 cells onto the STRT matrix containing these two antibodies produced approximately $20-30 \%$ reduction in cell growth. Immunostaining showed that both vitronectin and histidine-rich glycoprotein were present in the STRT protein matrix (data not shown). In addition to TNF/ActD killing, these tested antibodies failed to block STRT-induced resistance to killing by TNF alone (data not shown).

Under similar experimental conditions, neutralizing monoclonal antibodies $(2-4 \mu \mathrm{g} / \mathrm{ml})$ against TGF- $\beta \mathrm{s}(\beta 1$, $\beta 2$ and $\beta 3$ ) or TNF receptors (TNFRI and TNFRII) failed to abolish the STRT function in blocking TNF and TNF/ActD killing (data not shown). Furthermore, STRT functions could not be inactivated by a variety of protease inhibitors at 0.1-10 mM (data not shown). These inhibitors were PMSF, leuhistin, E64, leupeptin, $\alpha 2$-macroglobulin, chymostatin, bestatinal, pepstatinal and antipain. 


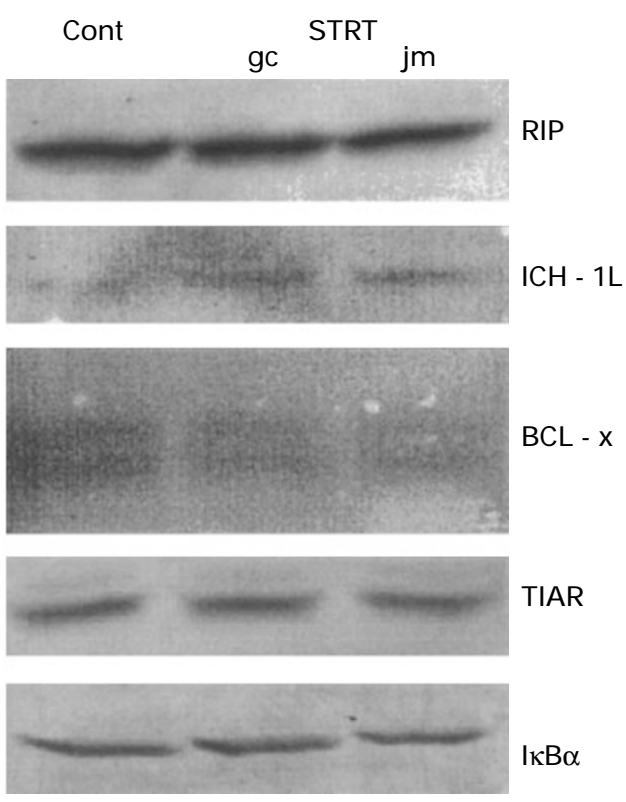

Figure 4 Failure of STRT in alteration of the expression of RIP, ICH-1 $\mathrm{L}_{\text {, }}$ BCL-x, TIAR and I $\kappa_{K} B$. L929 cells were seeded onto $60 \mathrm{~mm}$ petri dishes precoated with PBS buffer or STRT proteins from the 20\% ASP fractions of PMSF-treated sera from two healthy individuals ( $\mathrm{gc}$ and $\mathrm{jm}$ ). After culturing L929 on the STRT or buffer matrix for $24 \mathrm{~h}$, the cells were harvested and lysed. Ten microgram of the cell lysates were subjected to SDS - PAGE and Western blotting analyses using antibodies against RIP, ICH-1 $\mathrm{L}, \mathrm{Bcl}-\mathrm{x}, \mathrm{TIAR}$, and $\mathrm{I}_{\kappa} \mathrm{B} \alpha$. No alteration of the expression of RIP, ICH-1, BCL-x, TIAR and $I_{\kappa} B \alpha$ was observed. STRT could not induce degradation of $I_{\kappa} \mathrm{B} \alpha$. Similar results were observed by stimulation of L929 cells with STRT for $5 \mathrm{~h}$ (data not shown)

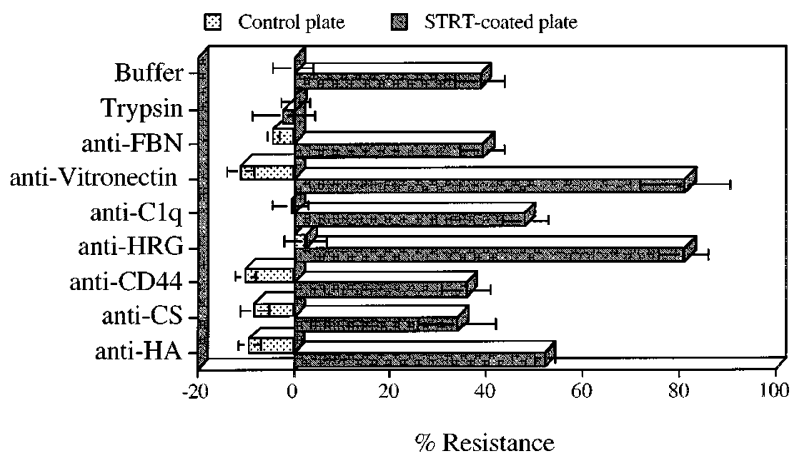

Figure 5 Abrogation of STRT function by trypsin, but not by antibodies against matrix proteins and cell surface components. Ninety-six well microtiter plates were coated with $30 \mu \mathrm{l}$ of the STRT-containing ASP fraction $20 \%$ from PMSF-treated serum for $3 \mathrm{~h}$ and then thoroughly washed. The STRT-coated wells were added $30 \mu \mathrm{l}$ of trypsin $(0.5 \mathrm{mg} / \mathrm{ml})$ or $1: 30$ diluted antisera agains fibronectin (FBN), vitronectin, complement $\mathrm{C} 1 \mathrm{q}$, histidine-rich glycoprotein (HRG), CD44, chondroitin sulfate (CS), or hyaluronic acid (HA), or PBS only, and incubated for $2 \mathrm{~h}$ at $37^{\circ} \mathrm{C}$, followed by washing three times with PBS. Similarly, blank or control 96-well microtiter plates were treated with trypsin, the above antisera, or PBS. L929 cells were than seeded onto these plates overnight, followed by testing their susceptibility to TNF (10 units $/ \mathrm{ml}) /$ ActD $(1 \mu \mathrm{g} / \mathrm{ml})$. Buffer: PBS buffer used as controls. Data are presented as mean \pm S.D. $(n=8)$. Trypsin significantly abolished STRT function $(P<0.01$, Student's $t$-tests). In the control plates, the coated antibodies had no significant effect in alteration of TNF/ActD killing $(P>0.1)$. In the STRT-coated plates, the induced resistance was not significantly reduced or increased by the tested antibodies $(P>0.1)$, except by anti-vitronectin and anti-HRG. These two antibodies significantly increased TNF/ActD resistance $(P<0.01)$

\section{Reversal of STRT function by protein tyrosine kinase inhibitors}

The STRT-mediated restriction of cell death by TNF and TNF/ActD could be reversed by protein tyrosine kinase inhibitors. For example, L929 cells were seeded onto STRT-coated matrix, cultured overnight, treated with protein tyrosine kinase inhibitors tyrphostin and lavendustin $A$ for $6 \mathrm{~h}$ and finally exposed to TNF or TNF/ActD for $24 \mathrm{~h}$. The results showed that protein tyrosine kinase inhibitors reversed the induced TNF or TNF/ActD resistance (Figure 6). However, H-7, a protein kinase C inhibitor, had no effect (Figure 6).

Under similar conditions, chemicals $(0.01-10 \mu \mathrm{M})$ which failed to reverse the STRT function were phosphatase inhibitors okadaic acid and tautomycin, and the activators of CAMP-dependent pathway forskolin and dibutyryl CAMP (data not shown).

\section{Inhibition of STRT-induced TNF resistance by AG-490, a selective JAK2 kinase inhibitor}

Next, we examined whether the selective JAK2 kinase inhibitor AG-490 (Meydan et al, 1996) and the selective MEK kinase inhibitor PD98059 (Pang et al, 1995) blocked the STRT function. Seeding of L929 cells onto the STRT matrix in the presence of AG-490 for $16 \mathrm{~h}$ resulted in a significant reduction of STRT function in blocking both TNF and TNF/ ActD killing, compared to buffer controls (Figure 7). In contrast, PD98059 had no inhibitory effect against STRT (Figure 7).

To examine whether NF- $\kappa \mathrm{B}$ is involved in STRTmediated protection of L929 cells against TNF killing,

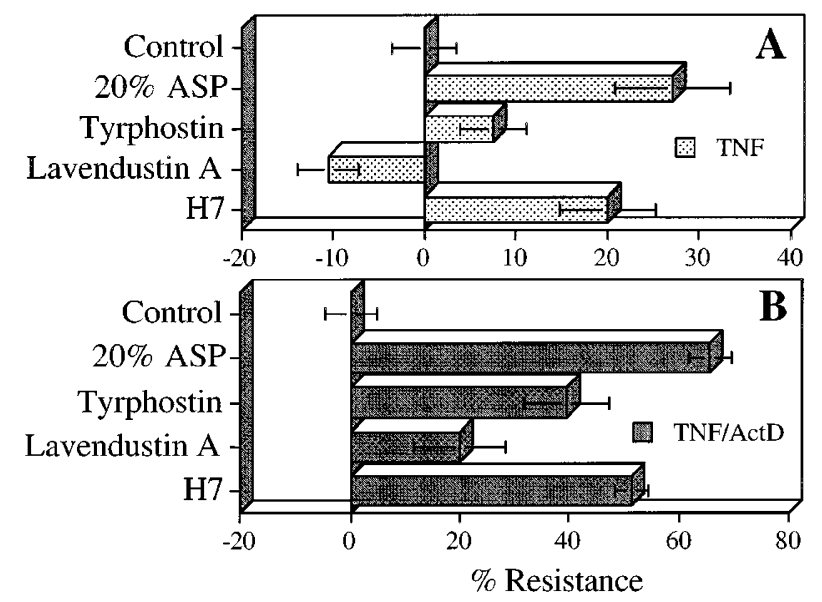

Figure 6 Protein tyrosine kinase inhibitors blocked STRT-induced TNFresistance. Thirty $\mu$ l aliquots of the $20 \%$ ASP fraction of PMSF-treated human serum were coated onto 96 -well plates for $3 \mathrm{~h}$ followed by thorough washing and seeding L929 cells. After culturing overnight, the cells were treated with or without $10 \mu \mathrm{M}$ protein kinase inhibitors for $6 \mathrm{~h}$ and then exposed to TNF (1000 units $/ \mathrm{ml})$ (A) or TNF (10 units $/ \mathrm{ml}) /$ ActD $(1 \mu \mathrm{g} / \mathrm{ml})$ (B) for $24 \mathrm{~h}$. Protein tyrosine kinase inhibitors lavendustin $A$ and tyrphostin significantly blocked the STRT-induced TNF- and TNF/ActD-resistance $(P<0.01$, Student's $t$-tests, $n=8)$, whereas the PKC inhibitor, $\mathrm{H} 7$, had no effect $(P>0.1)$. Control: PBS buffer only 
L929 cells were seeded onto the STRT matrix in the presence or absence of NF- $\kappa \mathrm{B}$ inhibitors curcumin (Singh and Aggarwal, 1995) and NF- $\kappa$ B SN50 (Lin et al, 1995) for $16 \mathrm{~h}$, followed by exposure to TNF or TNF/ActD for an additional 16-24 h. The results showed that both inhibitors failed to block the STRT-mediated TNF resistance (Figure 7). By raising the concentration of NF- $\kappa$ B SN50 from $10 \mu \mathrm{g} /$ $\mathrm{ml}$ to $50 \mu \mathrm{g} / \mathrm{ml}$, this inhibitor peptide still had no effect (data not shown).

\section{Reversal of the STRT-induced TNF resistance by testicular hyaluronidase}

As an extracellular matrix degrading enzyme, hyaluronidase is capable of enhancing TNF killing of L929 cells by preexposure of these cells to hyaluronidase for at least $12 \mathrm{~h}$ (Chang et al, manuscript submitted). To examine whether hyaluronidase reversed the protective function of STRT, L929 cells were seeded onto the STRT matrix overnight, followed by treatment with hyaluronidase for $8 \mathrm{~h}$ and coincubation with TNF for an additional $24 \mathrm{~h}$. The STRT-induced TNF resistance was abolished by hyaluronidase (Figure 8).

\section{Determination of the isoelectic points (pl) of STRT proteins}

The $20 \%$ human serum ASP fraction was subjected to preparative IEF and $30 \mu \mathrm{l}$ aliquots of the resulting fractions (20 fractions) were coated onto 96-well plates for $3 \mathrm{~h}$ for determination of the STRT activity. The plates were then washed and seeded with L929 cells for examining their
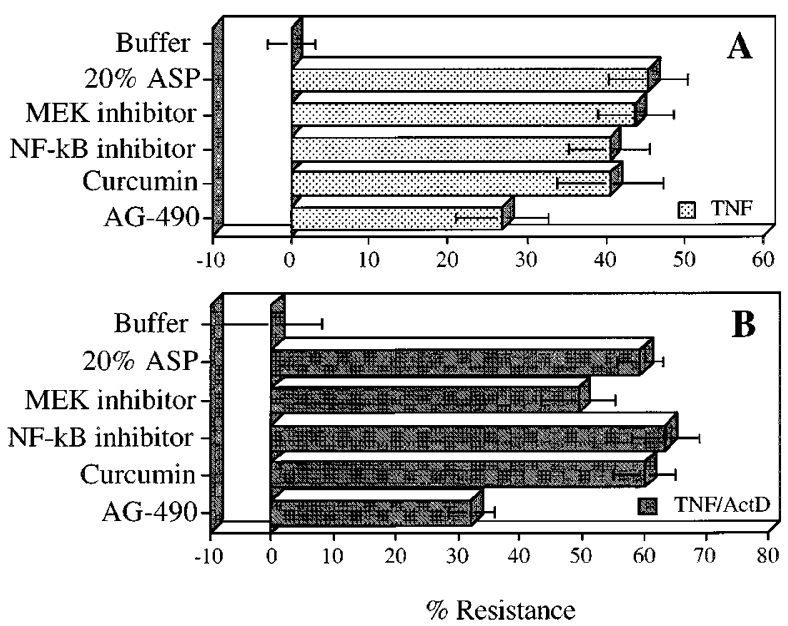

Figure 7 Reversal of STRT induced TNF resistance by AG-490, a selective inhibitor of JAK2 kinase. Thirty $\mu \mathrm{l}$ aliquots of STRT from the $20 \%$ ASP fraction of PMSF-treated serum were coated onto 96-well microtiter plates for $3 \mathrm{~h}$ at $37^{\circ} \mathrm{C}$ and then thoroughly washed. L929 cells were seeded onto the STRTmatrix and cultured overnight (16 h) in the presence or absence of PD98059 (MEK 1/2 inhibitor; $20 \mu \mathrm{M}$ ), a cell-permeable NF- $\kappa$ B inhibitor peptide (NF- $\kappa$ B SN50; $10 \mu \mathrm{g} / \mathrm{ml})$, curcumin $(20 \mu \mathrm{M})$, or AG-490 $(20 \mu \mathrm{M})$, followed by removal of these chemicals and exposure to TNF (1000 units $/ \mathrm{ml})(\mathbf{A})$ or TNF (10 units $/ \mathrm{ml}) /$ ActD $(1 \mu \mathrm{g} / \mathrm{ml})(B)$ for $24 \mathrm{~h}$. AG-490 significantly reduced $40.8 \%$ and $45.8 \%$ of STRT-increased resistance to TNF and TNF/ActD, respectively $(P<0.01$, $n=8$, Student's $t$-tests), whereas other chemicals failed to reduce the resistance $(P>0.1, n=8$, Student's $t$-tests) responsiveness to TNF and TNF/ActD. Two populations of STRT proteins were found to block TNF killing, which corresponded to the isoelectric points of $4.2-6.0$ (fractions

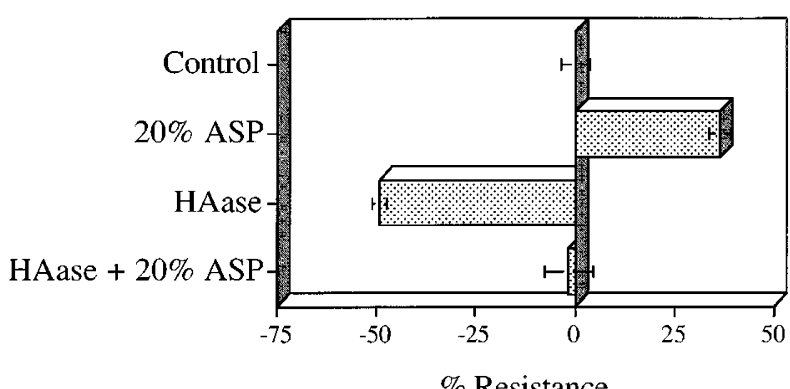

Figure 8 Reversal of STRT induced TNF resistance by hyaluronidase. L929 cells were seeded onto 96-well plates coated with human STRT from the $20 \%$ ASP of PMSF-treated serum for $24 \mathrm{~h}$, followed by exposure to testicular hyaluronidase $(50$ units $/ \mathrm{ml})$ for $8 \mathrm{~h}$ and finally coincubation with TNF (1000 units $/ \mathrm{ml}$ ) for $24 \mathrm{~h}$. In controls, L929 cells were seeded onto PBS buffer-coated plates and treated similarly. Hyaluronidase completely reduced the increased TNF resistance $(P<0.01, n=8$, Student's $t$-tests). HAase: hyaluronidase
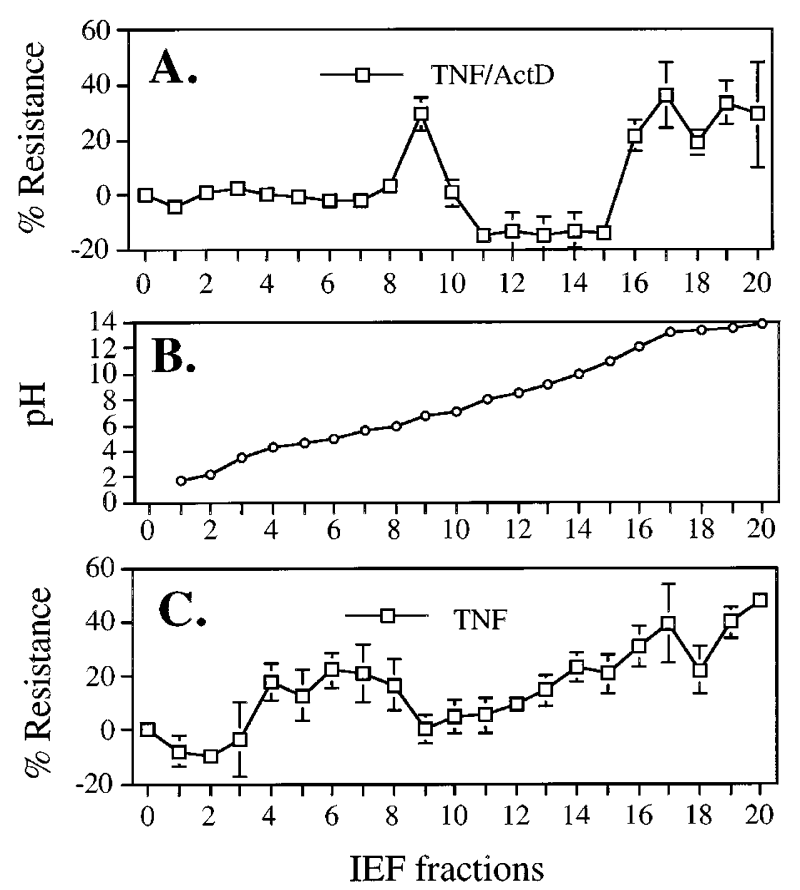

Figure 9 Determination of the isoelectric points (pl) of STRT by preparative IEF. The 20\% ASP fraction of PMSF-treated serum which contained STRT proteins was subjected to IEF as described in Materials and Methods. Ninetysix well microtiter plates were coated with $30 \mu \mathrm{l}$ of the serum IEF preparations (or PBS buffer) for $3 \mathrm{~h}$ at $37^{\circ} \mathrm{C}$, followed by thorough washing and seeding L929 cells overnight for testing their susceptibility to TNF (1000 units $/ \mathrm{ml}$ ) and TNF (10 units $/ \mathrm{ml}) / A c t D(1 \mu \mathrm{g} / \mathrm{ml})$. The fraction \#0 is the PBS buffer control. Two populations of STRT proteins were found to block TNF killing, which correspond to the isoelectric points (pl) of 4.2-6.0 (fractions \#4-8) and $9.9-13.8$ (fractions \#14-20). However, the inhibitory activity for the TNF/ActD killing is located at pl of 6.8 (fraction \#9) and 12.1-13.6 (fractions \#16-19). Resistance to killing for more than $20 \%$ is statistically significant as versus controls ( $P<0.01, n=8$, Student't $t$-tests) 
$\# 4-8)$ and 9.9-13.8 (fractions \#14-20) (Figure 9). However, the inhibitory activity for the TNF/ActD was located at pl of 6.8 (fraction \#9) and 12.1-13.6 (fractions $\# 16$-19) (Figure 9).

\section{Discussion}

In this study we demonstrated that human serum adhesive STRT proteins were capable of protecting L929 cells against death caused by serum deprivation, TNF, TNF/ActD and doxorubicin. In contrast, STRT failed to block cell death by ActD, anti-Fas/ActD and staurosporine. The underlying mechanism of this protective effect is unclear. However, in this study we have determined that STRT failed to alter the expression of proteins involved in apoptosis such as RIP, $\mathrm{ICH}-1_{\mathrm{L}}, \mathrm{BCL}-\mathrm{x}$, and TIAR. Further, no $\mathrm{I}_{\kappa} \mathrm{B} \alpha$ degradation was found by seeding L929 cells onto the STRT protein matrix. Notably, the reversal of the acquired TNF-resistance in STRTstimulated L929 cells by lavendustin A and tyrphostin suggests that activation of protein tyrosine kinases occurs in these cells.

Two likely STRT proteins of 226 and $265 \mathrm{kDa}$ were observed by comparing the protein profiles from the functional and nonfunctional ASP fractions from sera pretreated with or without PMSF. The functional properties and $\mathrm{pl}$ values of these two proteins remain to be established. We do not exclude the possibility of presence of other functional proteins. For example, results from the preparative IEF using the $20 \%$ ASP of PMSF-treated serum revealed that there were two apparent protein populations which conferred TNF and TNF/ActD resistance in L929 cells. The pl values for the TNF-inhibitory fractions were not identical to those of the TNF/ActD-inhibitory fractions, although these values were somewhat overlapping. These observations suggest that the STRT proteins which inhibit TNF killing may not be able to block TNF/ActD killing.

Like the $46-\mathrm{kDa}$ TRT protein produced by the TGF- $\beta 1$ stimulated L929 cells (Chang, 1995), STRT is resistant to treatment with high salt and protease inhibitors. L929 derived-TRT inhibits cell death by TNF/ActD, but not by TNF alone (Chang, 1995). In contrast, serum STRT blocks both TNF- and TNF/ActD-mediated killing. Most interestingly, TRT enhances L929 cell death by anti-Fas antibodies/ActD (Chang et al, unpublished), whereas STRT has no such effect. Tyrosine kinase inhibitors tyrophostin and lavendustin A block the activities of both STRT and TRT. However, $\mathrm{H} 7$, an inhibitor of protein kinase C (Kawamoto and Hidaka, 1984), blocks TRT function, but has no effect on the STRT function. Overall, our data indicate that cellular TRT is not identical to serum STRT.

The reversal of STRT function by tyrosine kinase inhibitors suggests that STRT-mediated TNF- or TNF/ ActD-resistance is related to activation of cellular proteintyrosine kinases. To explore the possible involvement of cellular tyrosine kinase pathways, we found that the selective MEK kinase inhibitor PD98059 (Pang et al, 1995) failed to block the STRT-induced TNF resistance, suggesting that STRT could not activate the Raf/MEK/MAP pathway (Marshall, 1995; Hunter, 1995; Davis, 1994; reviews). However, the STRT activity was partially inhibited by seeding L929 cells onto STRT protein matrix in the presence of AG-490, a selective inhibitor of JAK2 kinase (Meydan et al, 1996). These observations suggest that STRT protein matrix may contain growth factors which probably activate the cytokine/JAK/Stat pathway (Darnell et al, 1994; Ihle, 1995). The activation of JAK2 and STAT3 kinases is being confirmed in our laboratory.

Next we examined whether NF- $\kappa \mathrm{B}$ is involved in the STRT-mediated TNF resistance. NF- $\kappa$ B activation during TNF signaling has been shown to play an essential role in protecting cells against the TNF killing (Beg and Baltimore, 1996; Liu et al, 1996; Van Antwerp et al, 1996; Wang et al, 1996). In contrast, glutamate-elicited neuronal cell death involves the activation of $\mathrm{NF}-\kappa \mathrm{B}$, in which the cell death is inhibited by aspirin (Grilli, 1996). Furthermore, a L929 cell mutant, L929R, resists TNF killing even in the presence of ActD (Chang, 1995). That is, the intrinsic protection mechanism in L929R cells against TNF apoptosis is not related to NF- $\kappa \mathrm{B}$ activation and its mediated protective gene transcription. In this study, we found that STRT failed to induce $\mathrm{I} \kappa \mathrm{B} \alpha$ degradation, supporting the notion that there is no NF- $\kappa \mathrm{B}$ activation in STRT-stimulated L929 cells. Restriction of nuclear translocation of NF- $\kappa$ B by a cellpermeable inhibitor peptide (Lin et al, 1995) failed to abolish the STRT protective effect. Similarly, inhibition of $\mathrm{NF}-\kappa \mathrm{B}$ activation by curcumin (Singh and Aggarwal, 1995) could not block the STRT function. These observations indicate that $\mathrm{NF}-\kappa \mathrm{B}$ is not involved in the STRT-mediated protection of $L 929$ cells against TNF.

Testicular hyaluronidase-treated L929 cells have been shown to resist TNF- and Fas-mediated apoptosis in the presence of actinomycin $D$, doxorubicin, daunorubicin or cycloheximide (Chang, 1996). However, in the absence of actinomycin $\mathrm{D}$ or cycloheximide, the hyaluronidase-pretreated L929 cells indeed acquire an enhanced TNF sensitivity. That is, pretreatment of L929 cells with hyaluronidase for at least $12 \mathrm{~h}$, followed by exposure to TNF, results in an increased cell death (Chang et al, submitted). In this study we determined that hyaluronidase abolished the protective effect of STRT. This observation raises the possibility that hyaluronidase digests the hyaluronan side chains of STRT proteins, thereby abrogating the STRT function. Alternatively, the hyaluronidase enhancement of TNF killing of L929 cells overrides the protective function of STRT.

In summary, it is demonstrated in this study that serum STRT proteins are capable of stimulating L929 cells to resist death caused by TNF, TNF/ActD, doxorubucin and serum deprivation. Although its molecular nature is unknown, STRTmediated prevention of cell death is apparently involved in the activation of cellular protein tyrosine kinases.

\section{Materials and Methods}

\section{Cell line}

Murine TNF-sensitive L929 fibrosarcoma cells were cultured in RPMI1640 medium supplemented with $10 \%$ fetal bovine serum (FBS, Sigma Chemicals, St. Louis, MO), as previously described (Chang, 1995). 


\section{Ammonium sulfate precipitation (ASP) of sera and examination of STRT activity}

Initial purification and functional determination of STRT were performed as follows: Ten milliliter of normal human sera were diluted in $30 \mathrm{ml}$ in phosphate-buffered saline (PBS) in the presence or absence of $1 \mathrm{mM}$ phenylmethylsulfonyl fluoride (PMSF; Sigma). Sequential precipitation of serum proteins was performed at $4{ }^{\circ} \mathrm{C}$ using $10,15,20,30$ and $40 \%$ of ammonium sulfate, followed by resuspension of each precipitated protein fraction with $5 \mathrm{ml} \mathrm{PBS}$ and exhaustive dialysis against PBS.

The ASP protein fractions were then tested for STRT activity against L929 cell death by both TNF/ActD and TNF alone as previously described (Chang, 1995; Cao et al, 1996). Briefly, 10-80 $\mu \mathrm{l}$ of the protein fractions or PBS buffer only were precoated onto polystyrene-based 96-well microtiter plates (Corning Glass Works, Corning, NY) with lids on for $3 \mathrm{~h}$ or up to $16-24 \mathrm{~h}$ at $37^{\circ} \mathrm{C}$ in a humidified tissue culture incubator. The plates were washed twice with $150 \mu \mathrm{l}$ of sterile $5 \mathrm{M} \mathrm{NaCl}$, three times with sterile Milli-Q water (Millipore, Bedford, MA), and finally three times with sterile PBS. Where indicated, the plates were directly washed six times with $150 \mu \mathrm{l}$ of sterile PBS only. The amount of protein coated onto microtiter plates was analyzed by the BioRad Protein Assay (BioRad, Hercules, CA). One hundred microliter aliquots of $\mathrm{L} 929$ cells $\left(2.5 \times 10^{5} / \mathrm{ml}\right)$ were then dispensed onto these microtiter plates, cultured $24 \mathrm{~h}$ in RPMl-1640 medium supplemented with $10 \% \mathrm{FBS}$ at $37^{\circ} \mathrm{C}$, and then treated with recombinant TNF (1000 units/ml; Genzyme Corp., Boston, MA) or TNF (10 units $/ \mathrm{ml})$ in the presence of ActD $(1 \mu \mathrm{g} / \mathrm{ml}$; Sigma) for $24 \mathrm{~h}$. The cells were then fixed and stained with crystal violet $(2 \%$ in $50 \%$ methanol), washed with running tap water (to remove dead cells) and lysed by $33 \%$ acetic acid. The extent of cell death was measured by an automatic microtiter plate reader at OD $560 \mathrm{~nm}$ (SLT Labinstruments, Research Triangle Park, NC) and calculated as follows: \% Cell Death $=[(\mathrm{OD}$ from control cells $-\mathrm{OD}$ from TNF-treated cells $) / O D$ from control cells] $\times 100$. Where indicated, the percentages of TNFresistance induced by STRT were calculated as: \% Resistance $=[1-(\%$ TNF-killing of STRT-treated cells $/ \%$ TNF-killing of control cells)] $\times 100$ (Chang, 1995, 1996; Cao et al, 1996). Approximately $50 \%$ of control cell death was observed by using the indicated concentrations of TNF.

In addition to TNF and TNF/ActD, the STRT-stimulated and control L929 cells were subjected to serum deprivation for $24 \mathrm{~h}$, or challenged with anti-Fas antibodies $(500 \mathrm{ng} / \mathrm{ml}) / \operatorname{ActD}(1 \mu \mathrm{g} / \mathrm{ml})$, ActD $(10 \mu \mathrm{g} / \mathrm{ml})$, doxorubicin $(10 \mu \mathrm{g} / \mathrm{ml}$; Sigma), or staurosporine $(500 \mathrm{nM}$; Calbiochem, San Diego, CA; Tamaoki et al, 1986) for $24 \mathrm{~h}$. The extent of cell death was determined.

Modulation of STRT-mediated TNF-resistance by inhibitors of protein tyrosine kinases and protein kinase $C$ was examined. These inhibitors included lavendustin A (Onoda et al, 1989), tyrphostin (Gazit et al, 1989) and $\mathrm{H} 7$ (Kawamoto and Hidaka, 1984), which were from both Calbiochem and GIBCO/BRL (Gaithersburg, MD). Briefly, L929 cells were seeded onto 96-well microtiter plates precoated with or without the partially purified STRT proteins (from the $20 \%$ ASP fraction of PMSF-treated serum) and cultured overnight, followed by pretreatment with non-cytotoxic concentrations of protein kinase inhibitors for $6 \mathrm{~h}$, and subsequent exposure to TNF or TNF/ActD for $16-24 \mathrm{~h}$. Additional chemicals used to block STRT function were: inhibitors of protein phosphatases, okadaic acid and tautomycin (Gong et al, 1992) (Calbiochem); activators of the CAMP-dependent pathway, forskolin and dibutyryl cAMP (Uneyama et al, 1993) (Biomol, Plymouth Meeting, PA); a specific MEK kinas 1 \& 2 inhibitor, PD98059 (Pang et al, 1995)
(New England BioLab, Beverly, MA); a cell-permeable inhibitor peptide for blocking NF- $\kappa$ B nuclear translocation, NF- $\kappa$ B SN50 (Lin et al, 1995) (Biomol); an inhibitor of NF- $k \mathrm{~B}$ activation, curcumin (Singh and Aggarwal, 1995) (Sigma); a selective inhibitor of JAK2 kinase, AG-490 (Meydan et al, 1996) (Biomol).

Where indicated, the adhered STRT proteins were pretreated with trypsin $(0.5 \mathrm{mg} / \mathrm{ml})$ (Sigma), and inhibitors of serine and/or cysteine proteases and other proteases, including PMSF, leupeptin, $\alpha 2$ macroglobulin, chymostatin, bestatinal, pepstatinal, antipain, leuhistin and E-64 (from both Sigma and Alexis, San Diego, CA), followed by testing their protective activity against TNF- or TNF/ActD-mediated L929 cell death. Various antibodies used to inhibit STRT function were: anti-vitronectin (Telios Pharmaceuticals, San Diego, CA); antihistidine-rich glycoprotein (Chang et al, 1992); anti-fibronectin (Sigma); anti-complement C1q (Sigma); anti-CD44 (Endogen, Boston, MA); anti-chondroitin sulfate (Sigma); anti-hyaluronic acid (Serotec, Raleigh, NC); neutralizing monoclonal IgG antibodies against human TGF- $\beta$ s $(\beta 1-\beta 3)$ (Genzyme); neutralizing monoclonal IgG antibodies against human TNF receptor type I and II (R\&D, Minneapolis, MN).

\section{Western blotting}

To determine whether STRT altered the expression of proteins which are involved in apoptosis, Western blotting was performed. Briefly, L929 cells were seeded onto $60 \mathrm{~mm}$ petri dishes which were precoated with $1 \mathrm{ml}$ of PBS buffer or the STRT preparations from the $20 \%$ ASP fractions of PMSF-treated sera from two healthy individuals. Following $24 \mathrm{~h}$ culturing, the cells were harvested and lysed by a lysis buffer (Chang, 1995) and $10 \mu \mathrm{g}$ of the cellular proteins was used in the Western blotting (Chang, 1996). Antibodies used in

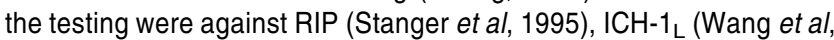
1994), BCL-x (Boise et al, 1993), TIAR (Taupin et al, 1995) and $\mathrm{l}_{\kappa} \mathrm{B} \alpha$ (Baeuerle and Baltimore, 1988; Miyamoto et al, 1994). These monoclonal antibodies were from Transduction Laboratories (Lexington, $K Y$ ), except that the anti- $\kappa_{\kappa} \mathrm{B} \alpha$ was from PharMingen (San Diego, CA).

\section{Preparative isoelectric focusing (IEF)}

Preparative IEF was performed using the Rotofor IEF apparatus (BioRad) as follows: $10 \mathrm{ml}$ of an STRT containing fraction from the $20 \%$ ASP fraction of PMSF-treated serum was diluted in $40 \mathrm{ml}$ sterile Milli-Q water containing $3 \mathrm{M}$ urea and $1 \mathrm{ml}$ Bio-Lyte ampholytes (pH 3-10; BioRad), and electrophoresed at 10 watt for $4 \mathrm{~h}$ at $4{ }^{\circ} \mathrm{C}$. Twenty protein fractions (around $2.5 \mathrm{ml}$ per fraction) were obtained and dialyzed exhaustively against $1 \mathrm{M} \mathrm{NaCl}$ to remove the ampholytes, followed by final dialysis against PBS. To determine the isoelectric points (pl) of STRT proteins, 96-well microtiter plates were coated with $30 \mu \mathrm{l}$ of the serum IEF preparations for $3 \mathrm{~h}$, followed by thoroughly washing the plates as indicated above, and seeding of L929 cells overnight for testing their susceptibility to TNF and TNF/ActD.

\section{Acknowledgements}

Research support to NSC was from the Wendy Will Case Cancer Fund, the National Institutes of Health grants R01-CA61879 and R55-CA64423. We appreciate the critical review of the manuscript by Dr. Gregory Carey, and the generous support from the Guthrie Foundation of Education and Research. We dedicate this article to NSC's beloved sister, who yielded her life to lung cancer on April 26, 1997, at 49. 


\section{References}

Baeuerle PA and Baltimore D (1988) I kappa B: a specific inhibitor of NF-kappa B transcription factor. Science 242: $540-546$

Beg AA and Baltimore D (1996) An essential role of NF- $\beta$ B in preventing TNF- $\alpha$ induced cell death. Science 274: 782-784

Belizario JE and Dinarello CA (1991) Interleukin 1, interleukin 6, tumor necrosis factor, and transforming growth factor beta increase cell resistance to tumor necrosis factor cytotoxicity by growth arrest in the $\mathrm{G} 1$ phase of the cell cycle. Cancer Res. 51: 2379-2385

Boise LH, Gonzalez-Garcia M, Postema CE, Ding L, Lindsten T, Turka LA, Mao X Nunez $\mathrm{G}$ and Thompson CB (1993) Bcl-x, a bcl-2-related gene that functions as a dominant regulator of apoptotic cell death. Cell 74: 597-608

Cao H, Mattison J, Zhao Y, Joki N, Grasso M and Chang N-S (1996) Regulation of tumor necrosis factor- and Fas-mediated apoptotic cell death by a novel cDNA, TR2L. Biochem. Biophys. Res. Commun. 227: 266-272

Chang N-S (1996) Hyaluronidase induces murine L929 fibrosarcoma cells resistant to tumor necrosis factor and Fas cytotoxicity in the presence of actinomycin D. Cell Biochem. Biophys. 27: 109-132

Chang N-S (1995) TGF- $\beta 1$ induction of novel extracellular proteins that trigger resistance to TNF cytotoxicity in murine L929 fibroblasts. J. Biol. Chem. 270: 7765-7772

Chang N-S, Leu RW, Rummage JA, Anderson JK and Mole JE (1992) Regulation of complement functional efficiency by plasma histidine-rich glycoprotein. Blood 79: $2973-2980$

Darnell JE Jr, Kerr IM and Stark GR (1994) Jak-STAT pathways and transcriptional activation in response to IFNs and other extracellular signaling proteins. Science 264: $1415-1421$

Davis RJ (1994) MAPKs: new JNK expands the group. Trends Biochem. Sci. 19: $470-473$

Gazit A, Yaish P, Gilon C and Levitzki A (1989) Tyrphostins I: synthesis and biological activity of protein tyrosine kinase inhibitors. J. Med. Chem. 32: 2344-2352

Gong MC, Cohen P, Kitazawa T, Ikebe M, Masuo M, Somlyo AP and Somlyo AV (1992) Myosin light chain phosphatase activities and the effects of phosphatase inhibitors in tonic and phasic smooth muscle. J. Biol. Chem. 267: 14662-14668

Grilli M, Pizzi M, Memo M and Spano P (1996) Neuroprotection by aspirin and sodium salicylate through blockade of NF- $\kappa$ B activation. Science 274: 1383-1389

Hunter T (1995) Protein kinases and phosphatases: the yin and yang of protein phosphorylation and signaling. Cell 80: 225-236

Ihle JN (1995) Cytokine receptor signaling. Nature 377: 591-594

Kamijo R, Takeda K, Nagumo M and Konno K (1988) Suppression of TNF-stimulated proliferation of diploid fibroblasts and TNF-induced cytotoxicity against transformed fibroblasts by TGF-beta. Biochem. Biophys. Res. Commun. 158: $155-162$

Kawamoto S and Hidaka H (1984) 1-(5-Isoquinolinesulfonyl)-2-methylpiperazine $(\mathrm{H}-7)$ is a selective inhibitor of protein kinase $\mathrm{C}$ in rabbit platelets. Biochem. Biophys. Res. Commun. 125: 258-264
Lin YZ, Yao SY, Veach RA, Torgerson TR and Hawiger J (1995) Inhibition of nuclea translocation of transcription factorNF-kappa B by a synthetic peptide containing a cell membrane-permeable motif and nuclear localization sequence. J. Biol. Chem. 270: 14255-14258

Liu ZG, Hsu H, Goeddel DV and Karin M (1996) Dissection of TNF receptor 1 effector functions: JNK activation is not linked to apoptosis while NF-kappaB activation prevents cell death. Cell 87: 565-576

Marshall CJ (1995) Specificity of receptor tyrosine kinase signaling: transient versus sustained extracellular signal-regulated kinase activation. Cell 80: 179-185

Meydan N, Grunberger T, Dadi H, Shahar M, Arpaia E, Lapidot Z, Leeder JS, Freedman M, Cohen A, Gazit A, Levitzki A and Roifman CM (1996) Inhibition of acute lymphoblastic leukaemia by a Jak-2 inhibitor. Nature 379: 645-648

Miyamoto S, Chiao PJ and Verma IM (1994) Enhanced $I_{\kappa} \mathrm{B} \alpha$ degradation is responsible for constitutive NF- $\kappa$ B activity in mature murineB-cell lines. Mol. Cell Biol. 14: 3276-3282

Onoda T, linuma H, Sasaki Y, Hamada M, Isshiki K, Naganawa H, Takeucmi T, Tatsuta K and Umezawa K (1989) Isolation of a novel tyrosine kinase inhibitor, lavendustin A, from Streptomyces griseolavendus. J. Natl. Prod. 52: 1252-1257

Pang L, Sawada T, Decker SJ and Saltiel AR (1995) Inhibition of MAP kinase kinase blocks the differentiation of PC-12 cells induced by nerve growth factor. J. Biol. Chem. 270: 13585-13588

Shepard HM and Lewis GD (1988) Resistance of tumor cells to tumor necrosis factor. J. Clin. Immunol. 8: 333-341

Singh S and Aggarwal BB (1995) Activation of transcription factor NF-kappa B is suppressed by circumin (diferuloylmethane) J. Biol. Chem. 270: 24995-5000

Stanger BZ, Leder P, Lee TH, Kim E and Seed B (1995) RIP: a novel protein containing a death domain that interacts with Fas/APO-1 (CD95) in yeast and causes cell death. Cell 81: 513-523

Sugarman BJ, Lewis GD, Eessalu TE, Aggarwal BB and Shepard HM (1989) Effects of growth factors on the antiproliferative activity of tumor necrosis factors. Cancer Res. 47: 780-786

Tamaoki T, Nomoto H, Takahashi I, Kato Y, Morimoto M and Tomita F (1986) Staurosporine, a potent inhibitor of phospholipid/Ca++dependent protein kinase. Biochem. Biophys. Res. Commun. 135: 397-402

Taupin JL, Tian Q, Kedersha N, Robertson M and Anderson P (1995) The RNAbinding protein TIAR is translocated from the nucleus to the cytoplasm during Fas-mediated apoptotic cell death. Proc. Natl. Acad. Sci. USA 92: 1629-1633

Uneyama H, Uneyama C and Akaike N (1993) Intracellular mechanisms of cytoplasmic Ca2+oscillation in rat megakaryocyte. J. Biol. Chem. 268: 168-174

Van Antwerp DJ, Martin SJ, Kafri T, Green DR and Verma IM (1996) Suppression of TNF- $\alpha$-induced apoptosis by NF- $\kappa$ B. Science $274: 787-789$

Wang C-Y, Mayo MW and Baldwin AS Jr (1996) TNF- and cancer therapy-induced apoptosis: Potentiation by inhibition of NF- $\kappa$ B. Science 274: 784-787

Wang L, Miura M, Bergeron L, Zhu H and Yuan J (1994) Ich-1, an Ice/ced-3-related gene, encodes both positive and negative regulators of programmed cell death. Cell 78: $739-750$ 